\title{
Retropharyngeal Space
}

National Cancer Institute

\section{Source}

National Cancer Institute. Retropharyngeal Space. NCI Thesaurus. Code C162824.

A neck space that is bounded anteriorly by the buccopharyngeal fascia, laterally by the carotid sheath, and posteriorly by the prevertebral fascia. 